\title{
R-CEPP Regimen
}

National Cancer Institute

\section{Source}

National Cancer Institute. R-CEPP Regimen. NCI Thesaurus. Code C154214.

A chemoimmunotherapy consisting of cyclophosphamide, etoposide, prednisone,

procarbazine (CEPP) and rituximab that can be used in the treatment of some forms of non-Hodgkin lymphoma (NHL). 